\title{
The impact of adjustment problems on academic achievement of international undergraduates at West Virginia University
}

Ke Zhao

West Virginia University

Follow this and additional works at: https://researchrepository.wvu.edu/etd

\section{Recommended Citation}

Zhao, Ke, "The impact of adjustment problems on academic achievement of international undergraduates at West Virginia University" (2006). Graduate Theses, Dissertations, and Problem Reports. 845.

https://researchrepository.wvu.edu/etd/845

This Thesis is protected by copyright and/or related rights. It has been brought to you by the The Research Repository @ WVU with permission from the rights-holder(s). You are free to use this Thesis in any way that is permitted by the copyright and related rights legislation that applies to your use. For other uses you must obtain permission from the rights-holder(s) directly, unless additional rights are indicated by a Creative Commons license in the record and/ or on the work itself. This Thesis has been accepted for inclusion in WVU Graduate Theses, Dissertations, and Problem Reports collection by an authorized administrator of The Research Repository @ WVU. For more information, please contact researchrepository@mail.wvu.edu. 
The Impact of Adjustment Problems on Academic Achievement of International Undergraduates at West Virginia University

Ke Zhao

Thesis submitted to the College of Human Resources and Education at West Virginia University in partial fulfillment of the requirements for the degree of

\author{
Master of Arts \\ in \\ Educational Psychology
}

Daniel Hursh, Ph. D., Chair

Floyd L. Stead, Ed. D.

Richard T. Walls, Ph.D.

Department of Advanced Educational Studies, Educational Psychology Program

\author{
Morgantown, West Virginia \\ 2006
}




\begin{abstract}
The Impact of Adjustment Problems on Academic Achievement of International

Undergraduates at West Virginia University

Ke Zhao
\end{abstract}

This research explored the correlation relationship between academic achievement and adjustment problems among international undergraduate students at West Virginia University. Michigan International Student Problem Inventory (M.I.S.P. Inventory) was used to measure the adjustment problems that international students have encountered. GPA scale was used to measure academic achievement. Thirty-three international undergraduate students participated this study. Students were asked to complete the survey and self-report GPA in the survey.

The correlations were found statistically significant between Academic Record problems and GPA, and between Social Personal problems and GPA. The Academic Record problems and Social Personal problems were both negatively correlated with GPA. Based upon both statistical and demographic results of this study, implications and recommendations were discussed towards the improvement of student affair services for international students on campus. Direction of future researches and the contributions of the current study were discussed in the end. 
Table of Contents

Chapter $1 \quad$ REVIEW OF LITERATURE......................................

Introduction.....................................................

Benefit of Having International Students..............................2

Adjustment Problems of International Students........................3

Adjustment Problems and Academic Achievement......................7

Adjustment Problems and Academic Retention........................8

Adjustment Problems and Self-Efficacy $. . . \ldots \ldots \ldots \ldots \ldots \ldots \ldots \ldots . \ldots . \ldots$

Personal Motivation of Thesis Topic...............................10

Motivation from Working Experience............................10

Significance of Study........................................11

Hypothesis and Research Questions................................12

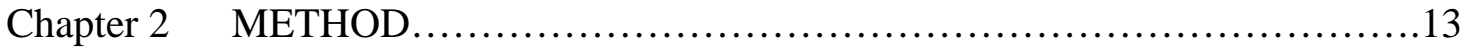

Participants..................................................13

Setting...................................................... 14

Instruments....................................................

Instrument Modification........................................16

Validity and Reliability of Instruments........................... 16

Design and Procedure............................................18

Chapter $3 \quad$ RESULTS.....................................................22

Statistic Significance of Correlations..............................22

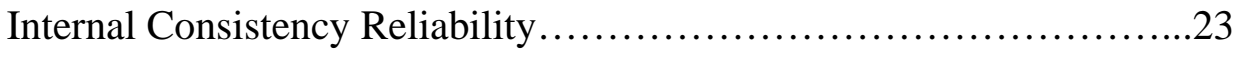

Frequency Distribution in Two Adjustment Areas......................24

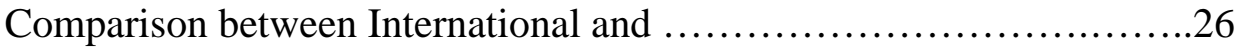

Non-international students in Counseling Services

Priority to Ask For Help..........................................27

Demographic Data and Narrative Feedback..........................28 


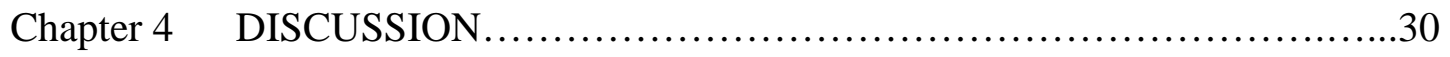

Limits of Research................................................... 30

Implication from Correlation Results...............................31

Implication for Counseling Services..................................31

Implication for Academic Advising..................................32

Implication for Recruitment and Retention...........................33

Implication for Office of International Students and Scholars............34

Recommendation for Future Research...............................35

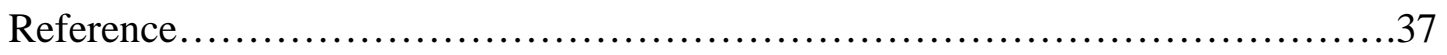

Appendix Figure 1: Priority Order to Ask for Help...............................40

Figure 2: Judgment of M.I.S.P. Inventory ............................41

Figure 3: Major Distribution......................................42

Figure 4: Language Distribution.....................................43

Figure 5: Residence and Citizenship Distribution.......................44

Figure 6: Distribution of Years at Previous and Present Colleges.........45

Figure 7: Age of Participants..................................................................46 


\section{Chapter 1}

\section{REVIEW OF LITERATURE}

\section{Introduction}

With a powerful education reputation and many kinds of funding to support study and research, U.S. higher education institutions attract numerous international students from all over the world every year. In the last two decades, the international student population studying in U.S. higher education institutions has increased constantly. In 1974, there were 154,580 foreign students in U.S. universities, and by 1994, the number reached roughly 450,000 (Open Doors, 2005). According to the annual report on international academic mobility supported from the U.S. Department of State's Bureau of Educational and Cultural Affairs, there are 565,039 students enrolled in U.S. higher education institutions in 2004-2005 after a slight drop of enrollment in 2003-2004 (Open Doors, 2005). Dina Habib Powell, Assistant Secretary of State for Educational and Cultural Affairs said, "The United States remains the best place in the world to pursue higher education and we continue to assure international students that they are welcome in our country” (Open Doors, 2005).

Under the circumstances of more international students being recruited into U.S. universities and U.S. higher education still maintains a positive attitude to international student population, it is important to study the characteristics of this population, especially their adjustment issues and problems when they are staying in the U.S. This is a necessary area that cannot be overlooked by student affairs professionals. The purpose 
of this research is to study the adjustment problems of international undergraduate students at West Virginia University, and to further analyze the relationship between their adjustment problems and academic achievement.

\section{Benefit of Having International Students}

International students bring significant economic benefits to U.S. institutions and the U.S. economy. They pay high out-of-state tuition because of their status. In 2004, international students spent $\$ 13.3$ billion dollars in the United States on their tuition and living expenses (Open Doors, 2005). This benefit continues even after they graduate and go back to their home countries. Most likely they will keep purchasing U.S. products and services, which not only creates more job opportunities for American people but also promotes international trade between the U.S. and other countries in the world (Peterson, Briggs, Dreasher, Horner, \& Nelson, 1986).

From an educational aspect, "international students enhance the academic excellence of the colleges and universities, because they are well prepared academically" (Wang, 2003). International students have respect for learning (Rai, 2002), and they are considered to be very serious and dedicated students (Lacina, 2002). They bring more challenges and multicultural understanding to classroom teaching and learning for American faculties and students. After international students return to their home countries, they can play an important role in developing further academic cooperation and connections as well (Rai, 2002). Many international students work as teaching assistants or research assistants in U.S. higher education institutions, because American 
students usually do not prefer these positions. This guarantees the sufficient supply of courses required by U.S. students (Peterson, Briggs, Dreasher, Horner, \& Nelson, 1986).

From the cultural aspect, "international students enrich the cultural diversity of campus” (Wang, 2003). Cultural diversity broadens the perspective of American students and develops mutual understandings between U.S. and other nations. Successful cultural integration is a very important component in today's globalization strategies and it has positive impact on U.S. higher education too. Peterson, Briggs, Dreasher, Horner and Nelson (1986) pointed out that some politicians and leaders who graduate from U.S. institutions usually play vital roles in national relationship and development with U.S. government.

Furthermore, international students themselves are the best recruiters! The students who have positive experience in U.S. institutions will bring a large group of reliable prospective students through their own networks. If the adjustment problems of current international students are well understood and solved, the positive experience from this group will help bring more potential benefit to U.S. higher education institutions in the future.

\section{Adjustment Problems of International Students}

In 1990, Hannigan gave the definition of adjustment as: "Adjustment can be conceptualized as a psychosocial concept which has to do with the process of achieving harmony between the individual and the environment.” He developed his definition based on the earlier research by Grove and Torbiorn (1985) who brought social and cognitive 
dimensions into the understanding of adjustment. Based upon his conclusion, the following main fields of adjustment problems of international students are explained.

1. Social loss

International students experience a sense of loss when they move to another country (Hayes \& Lin, 1994). International students leave behind the social network in their home countries seeking their educational goals in U.S. institutions, so that they have to establish a new social network and support system in a brand new environment that is completely different from the ones that traditional college students' have (Lacina, 2002). According to the research of Tompson (1996), developing a social network ranks the highest as the most difficult aspect of adjustment among all international students who participated in the surveys. He pointed out that the minimum threshold of comfort in social needs experienced by international students is a big determinant of international student classroom behavior, such as unwillingness to speak out or study with American students in class.

\section{Language difficulties}

Another prevalent adjustment problem for international students is language barrier. Lack of language proficiency is a barrier for international students to adapt to a new social environment (Lacina, 2002). Oral comprehension and communication skills can not be accurately measured by Test of English as a Foreign Language (TOEFL), thus sufficient English competency of international students, particularly in social situations, can not be guaranteed upon their admissions (Pederson, 1991). For example, some 
students may be adequately prepared for academic English in classroom settings, but not familiar with idioms and college slang (Lacina, 2002).

For international students who are from non-English-speaking countries, they usually experience more problems with the English language. In fact, those international students who are from English-speaking countries still experience language difficulties, such as exotic accents and use of different expressions (Mori, 2000).

Language difficulties have a direct impact on communication efficiency. Misunderstanding and misinterpretations in languages lead to negative attitude with relationships and social interaction.

3. Cultural shock

Cultural shock is the most frequently used term to describe the symptoms that people have when they are put into a new social and cultural environment. "Cultural shock refers to the negative aspect of cultural adjustment, and it is the normal process of adaptation to cultural stress” (Khoo \& Abu-Rasain, 1994). According to Pederson (1995), "cultural shock is the process of initial adjustment to an unfamiliar environment."

Cultural shock has a direct impact on adjustment problems. In the process of transition to a new culture, international students exhibit many symptoms owing to the stress from adjustment to a new culture, such as extreme loneliness, cultural shock and physical symptoms (Lacina, 2002). Reinicke (1986) pointed that there were four factors that influence cultural shock: (1) language proficiency, (2) social interaction, (3) national origin and perceived discrimination, and (4) depression across cultures and locus of 
control.

4. Cultural differences in communication patterns

U.S. culture is more direct than the culture in many Asian countries. Based upon the research of Hall (1976) on "high-context and low-context communication", Wang (2003) mentioned that American culture is a kind of low-context culture, whereas Chinese or Philippine's culture prefers high-context communication and indirectness in relationship. This is a good example to explain why some international students from Asian areas feel difficult to be understood by Americans in some occasions.

Another example of cultural differences in communication is the different understandings and perceptions in friendship pattern. The mobility and individual-oriented style of U.S. society determines that the friendship pattern in U.S. is less permanent and lasting. This friendship pattern is usually mistakenly interpreted by international students as the signal of serious friendship (Mori, 2000).

The difficulties in adjusting to new communication patterns of international students lead to their frustration and disappointment to set up friendship with Americans.

5. Anxiety from immigration limits

Unlike immigrants, international students have to report to various authorities to assure their legal status during their study in U.S. institutions (Khoo \& Abu-Rasain, 1994). For example, they need to report their address changes constantly and deal with visa and immigration documentation process. Extra stress and anxiety arise owing to their fear of being deported without completion of their education because of omission or 
violation of immigration regulations (Khoo \& Abu-Rasain, 1994).

6. Career decision-making after graduation

Whether staying in the host country or going back to the home countries is a big problem faced by international students upon their graduation, and this is a stressful process (Khoo \& Abu-Rasain, 1994). Mori (2000) pointed out that in this decision-making process, because international students might have changed their sense of identity, cultural values, customs, etc., in the host country, their decision-making on their future career plans is complicated.

The adjustment issues in career decision-making process of international students provided a good example of social cognitive framework presented by Lent, Brown and Hackett (1994). They acknowledged the influence of environmental conditions on career decision-making and the "importance of learning experience in interaction with person and contextual factor” (P. 85). At the same time, the points of Lent, Brown and Hackett (1994) provided a theoretical foundation to explain the particular characteristic of international students' adjustment issues in career choices from the perspective of social cognitive development.

\section{Adjustment Problems and Academic Achievement}

International students share the same academic stresses with American students, but their stresses are aggravated owing to their effort to fit into a brand new culture under the unfamiliar language and social environment. Adjustment issues of international students may become the major distraction factor that affects their academic achievement 
(Charles \& Stewart, 1991). "The faster they adjust, the faster they can get down to studying” (Khoo \& Abu-Rasain, 1994).

One of the biggest adjustment problems that international students encounter in the academic field is the different education system in U.S. higher education institutions. Different education systems require different study skills and outcomes (Khoo \& Abu-Rasain, 1994). Some international students' former learning styles, such as exam-oriented memorizing, quietness in the classroom, do not work in the classrooms in U.S. institutions in which active class discussion, oral presentation and pop-up quizzes put more weight on the final grades.

Another adjustment problem influencing their academic issues is language difficulty. Some international students, especially those from non-English-speaking countries, feel very difficult to understand lecture and participate less than American students in discussions (Tompson, 1996). Extra stress arises when international students face the pressure from the high expectation of success from home (Khoo \& Abu-Rasain, 1994), especially for those who are from Asian countries where the success and achievement in education is the symbol of status.

\section{Adjustment problems and Academic Retention}

For both student affairs professional and international students, academic program retention is the field through which the impact of adjustment problems on academic achievement can be identified as the reference to improve student service programs. The effect of adjustment problems of international students can influence academic retention, 
indicating student potential withdrawal tendency. Charles and Stewart (1991) mentioned that the adjustment issues of international students "tend to become significant distraction and may affect students’ academic performance.”

Rickinson and Rutherford (1995) identified 3 types of problems that influence academic retention rate: (1) academic unpreparedness, (2) emotional unpreparedness, and (3) family or financial responsibilities. According to Gillock (1999), during the first year at a university, students who were persistent place a higher value and importance on achieving academic goals, and they have higher first-semester grades than the dropouts.

\section{Adjustment Problems and Self-Efficacy}

Among the psychological variables that influence student academic achievement, self-efficacy is the important determinant to predict academic performance. Kalsner (1992) examined the relationship of self-efficacy to academic performance goals among college students. The results showed that self-efficacy influenced the students' ability to cope with obstacles and helped to understand their sense of helplessness to academic challenge. The study of Wratcher (1991) indicated that there were two major influence factors to academic achievement in students' freshmen year: (1) students' history of academic success, and (2) academic environment of the campus.

The research of Poyrazli (2001) showed that self-efficacy was associated with adjustment problems. The higher the level of academic self-efficacy, the fewer adjustment problems reported. Lent and Maddux (1997) emphasized the role of self-efficacy in behavior changes. They pointed out that "people's beliefs about their 
behavioral capabilities and their likelihood of coping with environmental demands and challenges” will affect the persistence of particular behavior (P. 243). For international student's population, the more they believe they are able to cope with academic obstacles, the better they will have less adjustment problems.

Personal Motivation for Thesis Topic

As one of the international students studying at WVU, I had encountered as many adjustment problems as other international students did. I've experienced the extra stress in the adjusting process and I am very curious to know the relationship between students' academic achievement and their adjustment problems. I feel it will be very practical and interesting to conduct research in this field. After reviewing a lot of literature, I've realized that my thesis topic not only can cover the knowledge in educational psychology, but also can be used as the reference to broader fields, such as college student development in higher education, counseling psychology, etc.

My confidence to conduct this research was further enhanced after meeting with directors and staff members in student affairs offices. They care about international student issues on campus and they are anxious to know my research result regarding international students' adjustment problems at WVU.

\section{Motivation from Working Experience}

Since fall 2004, I have been working as graduate assistant in the Office of International Students and Scholars (OISS) at WVU, assisting the International Recruitment Project. The International Recruitment Project provides academic and 
student affairs support for international students, develops and improves the educational environment and service of West Virginia University, and brings many benefits to international students. I am responsible for the development of recruitment procedures and strategies, advising prospective and current international students to proper information resources and supportive services, and creating a positive atmosphere among different student communities on campus.

Standing in the front line to help international students, I have observed many international students who have difficulty in coping with their problems from academic pressure and living problems, and who badly need guidance to reach supportive services. Is enough attention paid to the "person-environment fit" of international students from the university? Whether or not advertised environment provides sufficient supportive services to prepare new students for a new environment? Whether or not the existing additional stress from adjustment problems will impact academic achievement of international students? Whether or not international students who have serious adjustment problems can maintain a positive academic record and be persistent in their academic programs? Will the withdrawal and dropout tendency rate of international students decrease if better strategies are applied?

\section{Significance of Study}

As stated above, among the growing population of international students on U.S. university campuses, the adjustment problems and the academic achievement of international students may affect academic program retention. Charles and Stewart (1991) 
stated that helping international students "adjust to the demands of their respective programs and achieve academic success" are "the two fundamental objectives" in advising work.

Student affairs professionals at WVU can use the result of this investigation to better understand current situations of international students on campus and provide more effective supportive services. For example, the Caruth Center in WVU, which provides counseling service, can use the findings of this study as the reference to improve strategies when conducting psychotherapy with international students. As the main information and service center for international students, the Office of International Students and Scholars at WVU can use the results of this study to (1) better understand the reasons of withdrawal and drop-out, and (2) advise international students to proper service sources to help them achieve their goals after coming to WVU.

\section{Hypothesis and Research Questions}

The purpose of this study is to explore the relationship between adjustment problems and academic achievement of international undergraduates at West Virginia University. It is generally hypothesized that adjustment problems are correlated with academic achievement. Based upon the eleven categories of adjustment problems in the survey conducted in this research, it is specifically hypothesized that each of the eleven adjustment problems is correlated with academic achievement. 


\section{Chapter 2}

\section{METHOD}

\section{Participants}

International undergraduate students who had been enrolled as full-time students during the spring 2005 semester and fall 2005 at WVU were encouraged to participate. There were nearly 300 international undergraduate students enrolled as full-time students for the semester spring 2005, and nearly 320 for the semester fall 2005.

There were several reasons for selecting undergraduates as participants. First, international undergraduate students need to make transition from high school to college, and at the same time they need to overcome extra stress owing to the difficulties in adjusting to a new cultural environment.

Second, international undergraduate students make a significant economic contribution to U.S. higher educational institutions. The financial status of international undergraduates is different from graduate students and exchange scholars--there are very few positions available for them to obtain research jobs or an assistantship at school, and they are restricted from applying for federal financial aid or work-study opportunities owing to immigration regulations on international students. The majority of undergraduate international students are supported by personal or family sources. According to the data from Open Doors (2005), 81\% of undergraduate students relied upon personal and family funding as the primary source of funds in year 2004-2005.

Another reason for selecting undergraduate international students is that the 
recruitment project in the Office of International Students and Scholars (OISS) at WVU mainly deals with the procedures and strategies for recruiting undergraduate international students. This group has been bringing a substantial amount of money to WVU every year. If the positive trend of recruitment and retention is maintained and increased, it will bring more benefit to WVU, and their adjustment problems can be a big determinant of their academic performance and retention rate.

\section{Setting}

Surveys were conducted under both personal and web-based settings. From mid April 2005 until the end of June 2005, the web-based survey was used. The survey announcement was sent out as one message to all participants through the email system from the Office of International Students and Scholars (OISS). A cover letter to all participants stating the purpose and the confidentiality of this online survey was composed in the beginning of the online survey web page. WebCT from WVU provided technical support to this online survey.

From July 2005 until September 2005, paper surveys were delivered. There were two main reasons. First, WebCT terminated its supportive service for student usage in the end of June 2005, changing its form to instruction purpose. Second, it was very difficult to get the sufficient number of participants to access the online survey during their summer vacation. Many of them went back to their home country for visit, or travel to other places where Internet service was not available. In order to collect as many data as possible, the paper survey was distributed during this period of time. Classrooms, 
computer labs, libraries, and other possible places on campus where international undergraduate students were likely to be, were the places to collect data. Paper survey forms were also placed in the reception table of Carruth Center of Counseling for any clients belonging to the research group to complete.

From late September 2005 until the end of October 2005, the web-based online survey was adopted again. This time, the format of technique service had changed from WebCT to be Simpleform that was more compact in version and was created to support research surveys from WVU. The survey announcement was sent out as one message to all participants again through the email system from OISS. A follow-up message regarding the online survey was sent out two weeks after the release of the original message.

\section{Instruments}

Michigan International Student Problem Inventory (M.I.S.P. Inventory) was used to measure the adjustment problems that international students have encountered. GPA scale was used to measure participants' academic achievement. Students were asked to self-report their GPA in the survey.

M.I.S.P. Inventory was developed by John W. Porter in 1962 and revised in 1977. This measurement was designed to identify the adjustment problems encountered by international students. There were two primary reasons for selecting the M.I.S.P. Inventory. First, the purpose of this study was to find out the correlation between adjustment problems and academic achievement among international students, and 
M.I.S.P. Inventory provided a reliable tool to identify adjustment problems. Thus, the M.I.S.P. Inventory pinpointed specific adjustment problems of international students at WVU. Second, by using M.I.S.P. Inventory in the most current situation, the result of this study can be compared with former research as the reference to conduct further research.

GPA rating was used as the indicator of student academic achievement. GPA is widely used by instructors and faculties to report college student academic achievement. Participants were asked to “self-report” their current cumulative GPA online at the same time as completing survey questions on adjustment problems.

\section{Instrument Modification}

To better protect human subjects, it was announced that the survey was confidential, and no personal name would be identified. However, the last question in the M.I.S.P. Inventory on page "Step Three” asked students to write down their names if they would like to discuss their concerns with someone. Upon the discussion and the agreement with the author of M.I.S.P. Inventory, Dr. John Porter, this question was changed to be: "If you find out that you need help to cope with your problems, you could ask for help from the Office of International Students and Scholars at 293-3519, or contact Caruth Center for counseling at 293-4431.” The same changes had been made in the online version to protect the confidentiality of all subjects as well.

Validity and Reliability of Instruments

M.I.S.P. Inventory (Michigan International Student Problem Inventory). Porter (1966) tested the concurrent validity and content validity of this instrument. Regarding 
concurrent validity, two groups of students, foreign students and American students, were administered the M.I.S.P. Inventory and MPCL (Mooney Problem Check List) separately. The results from M.I.S.P. Inventory showed a significant difference $(t=5.08)$ between the means score of 108 foreign students $(M=15.06)$ and 50 American students $(M=11.26)$ at the .05 level. The results from MPCL showed a significant difference $(t=4.67)$ at the .05 level between mean score of 46 foreign students $(M=21.24)$ and 47 American students $(M=44.97)$. The results from both tests showed significant group difference at the .05 level, which supports the concurrent validity of the M.I.S.P. Inventory as an effective instrument to better pinpoint problems of foreign students.

Regarding content validity, the result showed a significant difference (Chi Square $=31.59$ ) at the .05 level, between the proportion of items checked at least once by foreign students and American students. Thus Porter's work supported the content validity of M.I.S.P. Inventory, indicating that many items that measure adjustment problems were unique to foreign students.

Porter (1966) selected Spearman-Brown split-half method and Kuder-Richardson formula to test the internal consistency reliability of the scores of the 108 foreign students. The total scale reliability estimates were .67 and .58 respectively. By using Kuder-Richardson formula, for each of the 11 sub-scale categories, the correlation coefficients ranged from .47 to .76.

GPA. According to the in-depth research and report by Cassady (2001) on self-report GPA and SAT score, self-reported values for GPA were shown to be reliable. Through the 
examination of results from 98 undergraduate students, the correlation between self-reported and actual cumulative GPA was found to be very high $(r=.97)$. This research also demonstrated that even though there was a trend that students with lower GPA values would inflate score ratings more than students with higher GPA values, no significant effect was found in direction of deviation between the two groups. Thus self-reported GPA was shown to be accurate. Cassady (2001) also stated that the use of self-report GPA would effectively avoid the limit to access into official records and make use of this variable easier for researchers, without a significant compromise in accuracy.

\section{Design and Procedure}

Because this study is to determine how strong the relationships between adjustment problems and academic achievement are, a correlational study was designed to analyze the data among adjustment problems and GPA ratings. M.I.S.P. Inventory consists of eleven categories of adjustment problems related to student personnel services: (1) admission-selection problems, (2) orientation service problems, (3) academic record problems, (4) social-personal problems, (5) living-dining problems, (6) health service problems, (7) religious service problems, (8) English language problems, (9) student activity problems, (10) financial aid problems, and (11) placement service problems. Twelve problems were listed under each of these eleven categories, making total 132 items in this inventory. Participants were asked to circle the item number if the stated problems troubled them, and to place an $\mathrm{X}$ in the circle if the problems were of most concern to them. Thus, under each of 11 categories, each of the 12 items was rated as (1) 
not concerned, (2) concerned, or (3) most concerned. The range for each of the 11 categories was 12 to 36 . Because adjustment problems can be considered as continuous variables in this design, and GPA is a continuous variable too, Pearson $r$ was used to measure the correlation relationships between GPA and the 11 categories.

The following table describes the 11 correlation relationships between adjustment problems and academic achievement that needed to be assessed:

Table 1

Correlation Relationships between Adjustment Problems and Academic Achievement (GPA)

\begin{tabular}{|l|l|l|}
\hline Problem Areas & $\begin{array}{l}\text { Score } \\
\text { Ranges }\end{array}$ & Correlations \\
\hline 1. Admission-Selection Problems & $12-36$ & $\begin{array}{l}\text { Pearson correlation between } \\
\text { admission-selection problems and } \\
\text { academic achievement (GPA) }\end{array}$ \\
\hline 2. Orientation Service Problems & $12-36$ & $\begin{array}{l}\text { Pearson correlation between orientation } \\
\text { service problems and academic } \\
\text { achievement (GPA) }\end{array}$ \\
\hline 3. Academic Record Problems & $12-36$ & $\begin{array}{l}\text { Pearson correlation between academic } \\
\text { record problems and academic } \\
\text { achievement (GPA) }\end{array}$ \\
\hline 4. Social-Personal Problems & $12-36$ & $\begin{array}{l}\text { Pearson correlation between } \\
\text { social-personal problems and academic } \\
\text { achievement (GPA) }\end{array}$ \\
\hline 5. Living-Dining Problems & $12-36$ & $\begin{array}{l}\text { Pearson correlation between } \\
\text { living-dinning problems and academic } \\
\text { achievement (GPA) }\end{array}$ \\
\hline 6. Health Service Problems & $12-36$ & $\begin{array}{l}\text { Pearson correlation between health } \\
\text { service problems and academic } \\
\text { achievement (GPA) }\end{array}$ \\
\hline 7. Religious Problems & $12-36$ & $\begin{array}{l}\text { Pearson correlation between religious } \\
\text { problems and academic achievement } \\
\text { (GPA) }\end{array}$ \\
language problems and academic \\
achievement (GPA)
\end{tabular}




\begin{tabular}{|l|l|l|}
\hline 9. Student Activity Problems & $12-36$ & $\begin{array}{l}\text { Pearson correlation between student } \\
\text { activity problems and academic } \\
\text { achievement (GPA) }\end{array}$ \\
\hline 10. Financial Aid Problems & $12-36$ & $\begin{array}{l}\text { Pearson correlation between financial } \\
\text { aid problems and academic } \\
\text { achievement (GPA) }\end{array}$ \\
\hline 11. Placement Service Problems & $12-36$ & $\begin{array}{l}\text { Pearson correlation between placement } \\
\text { service problems and academic } \\
\text { achievement (GPA) }\end{array}$ \\
\hline
\end{tabular}

In the beginning of the online survey, all international undergraduate students received a message in their school email account. The link access to the survey questions was provided. Then, the participants were asked to click the options of questions and input their answers to the survey. An Excel document listing all data results was obtained at the end of the online survey through WVU Web Services. These data were collected online by the end of October 2005.

In the process of conducting paper surveys, the circumstance was personal and more varied compared to the online survey. In summer vacation, the population of international undergraduate students was distributed in summer classes, libraries, and some areas near campus. Some paper surveys were conducted near OISS, especially when the individuals came to OISS asking for regular services. Some paper surveys were conducted in the classrooms, computer labs, or libraries where international undergraduates were studying. The most paper surveys were distributed through personal friends of the research group and other friends through them. Thirty completed survey were collected in the form of the paper survey. 
At the same time, the demographic data about the number of international students and non-international students who went to the Carruth Center of Counseling at WVU from fall 2002 to fall 2005 were acquired under the support of the director of the Carruth Center of Counseling. The information of enrollment number of international students and non-international students at WVU from fall 2002 to fall 2005 was obtained through the help of the Office of International Students and Scholars (OISS) and the Office of Admissions and Records at WVU. 


\section{Chapter 3}

\section{RESULTS}

\section{Statistical Significance of Correlations}

Based upon the survey results from 33 participants, scores were obtained from the M.I.S.P. Inventory and used to calculate the values of Pearson $r$ to evaluate the correlation between the eleven categories of adjustment problems and GPA. The results showed that the correlations were statistically significant between Academic Record problems and GPA, and between Social Personal problems and GPA. The Academic Record problems and Social Personal problems were both negatively correlated with GPA. The more adjustment problems identified in these two categories, the lower the GPA reported. The correlations between GPA and the other 9 problem categories in M.I.S.P. Inventory were not statistically significant. The original hypothesis that "each of the eleven adjustment problems is correlated with academic achievement” was partially supported.

The correlation relationship between the adjustment problems in 11 categories and GPA was calculated separately by using Pearson $r$. The results showed that the correlations between academic record problem and GPA, and between social personal problem and GPA were statistically significant (See Table 2).

Table 2

Correlations of GPA with 11 Sub-scale Categories of Adjustment Problems

\begin{tabular}{|l|l|l|l|}
\hline GPA with: & N & $\begin{array}{l}\text { Pearson } \\
\text { Correlation }\end{array}$ & $\begin{array}{l}\text { Significance } \\
\text { (2-tailed) }\end{array}$ \\
\hline
\end{tabular}




\begin{tabular}{|l|l|l|l|}
\hline 1. Admission-Selection Problems & 33 & -0.67 & .712 \\
\hline 2. Orientation Service Problems & 33 & -.265 & .136 \\
\hline 3. Academic Record Problems & 33 & -.384 & $.028 *$ \\
\hline 4. Social-Personal Problems & 33 & -.362 & $.038 *$ \\
\hline 5. Living-Dining Problems & 33 & -.119 & .511 \\
\hline 6. Health Service Problems & 33 & -.155 & .389 \\
\hline 7. Religious Problems & 33 & -.158 & .378 \\
\hline 8. English Language Problems & 33 & -.141 & .434 \\
\hline 9. Student Activity Problems & 33 & -.301 & .089 \\
\hline 10.Financial Aid Problems & 33 & -.282 & .112 \\
\hline 11.Placement Service Problems & 33 & -.236 & .185 \\
\hline
\end{tabular}

Note: * indicates $p<.05$

Internal Consistency Reliability

Cronbach's alpha was used to estimate internal consistency reliability of the

M.I.S.P. Inventory. Because the items in the M.I.S.P. Inventory were rated on three-point scale (1,2, and 3), Crobach's alpha was the appropriate method for analysis of internal consistency reliability. A reliability estimate of .89 was found for the total scale (across all 11 sub-scales, 132 items) by using Crobach’s alpha. Table 3 provides information on the means, standard deviations, and reliability coefficients of the 11 sub-scale categories

of the M.I.S.P. Inventory:

Table 3

Sub-Scale and Total Scale Mean, Standard Deviation and Crobach's alpha for the M.I.S.P Inventory

( $N=33$ participants)

\begin{tabular}{|l|l|l|l|l|}
\hline Sub-Scales & Items & Mean & S.D. & Crobach's alpha \\
\hline 1. Admissions-Selection & 12 & 1.21 & .22 & .602 \\
\hline 2. Orientation Services & 12 & 1.21 & .17 & .456 \\
\hline 3. Academic Records & 12 & 1.34 & .28 & .696 \\
\hline 4. Social-Personal & 12 & 1.28 & .21 & .523 \\
\hline 5. Living-Dining & 12 & 1.22 & .21 & .629 \\
\hline 6. Health Services & 12 & 1.32 & .35 & .423 \\
\hline 7. Religious Services & 12 & 1.09 & .15 & .620 \\
\hline 8. English Language & 12 & 1.48 & .36 & .799 \\
\hline
\end{tabular}




\begin{tabular}{|l|l|l|l|l|}
\hline 9. Student Activities & 12 & 1.19 & .16 & .257 \\
\hline 10.Financial Aids & 12 & 1.27 & .26 & .727 \\
\hline 11.Placement Services & 12 & 1.24 & .23 & .612 \\
\hline Total Scale & 132 & 1.26 & .14 & .890 \\
\hline
\end{tabular}

According to the data in Table 3, it is observed that each subscale internal consistency coefficient is lower than the total scale internal consistency coefficient. There are two main reasons leading to this problem. First, because less items were included in subscale, which automatically lower the Crobach's alpha value in subscale. Another reason is the variability of the items associated with each scale. The lowest value (.257) has the most variability across items whereas the highest value (.799) has the least variability in term of internal consistent.

Frequency Distribution in Two Adjustment Areas

As noted in the previous results, GPA was negatively correlated with Academic Record Problems and Social Personal Problems. The following statistical tables (Table 4 and Table 5) provide the frequency distribution of the items in Academic Record Problems and Social Personal Problems from the 33 participants.

Table 4

Frequency Distribution on Academic Record Problems ( $N=33$ participants)

\begin{tabular}{|l|r|r|r|}
\hline Content & $\begin{array}{l}\text { Not } \\
\text { concerned }\end{array}$ & Concerned & $\begin{array}{l}\text { Most } \\
\text { Concerned }\end{array}$ \\
\hline Frequent college examinations & 19 & 12 & 2 \\
\hline Compulsory class attendance & 30 & 2 & 1 \\
\hline Writing or typing term (semester) papers & 12 & 14 & 2 \\
\hline Competitive college grading system & 25 & 6 & 2 \\
\hline Objective examinations (true-false, etc.) & 30 & 1 & 2 \\
\hline Insufficient advice from academic advisor & 22 & 9 & 2 \\
\hline Too many interference with studies & 29 & 2 & 2 \\
\hline
\end{tabular}




\begin{tabular}{|l|r|r|r|}
\hline Feel unprepared for U.S. college work & 29 & 3 & 1 \\
\hline Concerned about grades & 18 & 11 & 4 \\
\hline Doing laboratory assignment & 22 & 7 & 4 \\
\hline Insufficient personal help from professor & 26 & 5 & 2 \\
\hline Relationship between U.S. students & 29 & 3 & 1 \\
\hline
\end{tabular}

Table 5

Frequency Distribution on Social Personal Problems $\quad$ ( $N=33$ participants)

\begin{tabular}{|l|r|r|r|}
\hline Content & $\begin{array}{l}\text { Not } \\
\text { Concerned }\end{array}$ & Concerned & $\begin{array}{l}\text { Most } \\
\text { Concerned }\end{array}$ \\
\hline Concern about becoming too “westernized” & 29 & 4 & 0 \\
\hline Insufficient personal-social counseling & 26 & 6 & 0 \\
\hline Being in love with someone & 32 & 1 & 3 \\
\hline Being lonely & 19 & 11 & 2 \\
\hline Feeling inferior to others & 20 & 11 & 2 \\
\hline Trying to make friends & 21 & 10 & 5 \\
\hline Sexual customs in United States & 25 & 3 & 0 \\
\hline Homesickness & 9 & 12 & 0 \\
\hline Feeling superior to others & 33 & 0 & 2 \\
\hline $\begin{array}{l}\text { U.S. emphasis on personal habits of } \\
\text { cleanliness }\end{array}$ & 32 & 1 & 3 \\
\hline Not feeling at ease in public & 25 & 6 & 4 \\
\hline Attitude of some U.S. people to skin color & 26 & & \\
\hline
\end{tabular}

According to the frequency distribution of Academic Record Problems (Table 4),

"Writing or typing term (semester) papers” ranked as the highest frequency among all “concerned” and “most concerned” items by the participants, which was consistent with the research reviewed on the important relationship between adjustment problems and academic achievement. It also contributes to the significant negative correlation between Academic Record Problems and GPA. The big concerns on writing or typing term papers constitute an obstacle to academic achievement. Two other strong concerns were 
"frequent college examinations” and “concerned about grades.”

The data from the frequency distribution of Social Personal Problem (Table 5) showed that "homesickness," "being lonely," and "feeling inferior to others" have the most frequency in "concerned” area of Social Personal Problems. This result was consistent with the former researches on international students' adjustment problems in "Social loss" and "Cultural shock.” The stronger their sense of "being lonely," "homesickness," and "feeling inferior to others," the more negative impact was put on their academic achievement. Thus, the correlation between Social Personal Problems and GPA was negative.

Comparison between International and Non-international Students in Counseling

\section{Services}

According to the data provided by the Carruth Center of Counseling, the Office of International Students and Scholars (OISS), and the Office of Admissions and Records, the proportions of international students and non-international students who went for counseling services out of the whole enrolled population of each group were calculated in the following table.

Table 6

The Proportion of International and Non-International Students Who Went For Counseling Services (Fall 2002—Fall 2005)

\begin{tabular}{|l|l|l|l|l|l|l|}
\hline Semesters & $\begin{array}{l}\text { Int. } \\
\text { Students } \\
\text { Enrolled }\end{array}$ & $\begin{array}{l}\text { Int. Students } \\
\text { in Coun } \\
\text { Services }\end{array}$ & $\begin{array}{l}\text { Proportion of } \\
\text { Int. Students in } \\
\text { Coun Services }\end{array}$ & $\begin{array}{l}\text { Non- } \\
\text { Int. } \\
\text { Students } \\
\text { Enrolled }\end{array}$ & $\begin{array}{l}\text { Non- } \\
\text { Int. Students } \\
\text { in Coun } \\
\text { Services }\end{array}$ & $\begin{array}{l}\text { Proportion } \\
\text { of Non-Int. } \\
\text { Students in } \\
\text { Coun } \\
\text { Services }\end{array}$ \\
\hline
\end{tabular}




\begin{tabular}{|l|l|l|l|l|l|l|}
\hline Fall 2002-Spring 2003 & 2,602 & 5 & $0.19 \%$ & 42,817 & 176 & $0.41 \%$ \\
\hline Fall 2003-Spring 2004 & 2,715 & 17 & $0.62 \%$ & 44,636 & 845 & $1.89 \%$ \\
\hline Fall 2004-Spring 2005 & 2,517 & 23 & $0.91 \%$ & 46,328 & 921 & $1.98 \%$ \\
\hline Fall 2005 & 1,244 & 11 & $0.88 \%$ & 24,807 & 401 & $1.6 \%$ \\
\hline
\end{tabular}

Note: Int.=International; Non-Int =Non-International; Coun=Counseling.

From the data of the proportion of international and non-international students

who went for counseling services from fall 2002 to fall 2005, it was obvious that in each

academic year, the proportion of non-international students who were in counseling services was beyond the proportion of international students who were in counseling services. This result indicated that when compared to non-international students at WVU, international students did not sufficiently use the counseling services available on campus.

The same results were mentioned by the studies of Lacina (2002) and Mori (2000), in which they pointed out that mental health services were underused by international students even though many of them needed psychological help. "Foreign students will rarely seek help with personal problems, even though they are troubled by them” (Khoo \& AbuRasain, 1994).

Priority Orders to Ask for Help and Judgment of M.I.S.P. Inventory by 33 Participants

The statistical data on "priority resource to ask for help” (See Figure 1 in Appendix ) provided evidence on the preference of international students when seeking help on campus. "Fellow students from their own countries" ranked the highest among their first choices, whereas “counselor” ranked as the $8^{\text {th }}$ among their first choices. In their second choices, “fellow students from their own countries” still ranked the highest, and “counseling” ranked as the $4^{\text {th }}$ level among all their second choices. This result was 
consistent with the points from Furnham and Alibhai (1985)—international students preferred to ask for help from their co-national friends "because of language and cultural similarities.” The finding also was consistent with the results from Baloglu (2000) in which counseling services were found underutilized by international students, and friends were reported to be the most preferred source for help by international students. Pederson (1991) also cited from his study that most of international students went to their fellow national friends for help, because they felt this resource was accessible and acceptable to them.

Figure 2 provided a picture regarding the brief judgment concerning the M.I.S.P. Inventory instrument. Most of students provided positive feedback—-they believed that the items in M.I.S.P. Inventory provided a fairly complete picture of their problem areas, and this survey was worthwhile in helping them identify their problems.

\section{Demographic Data and Narrative Feedback}

Demographic information from 33 participants was analyzed into five figures (See Figure 3 through Figure 7 in Appendix). Figure 3 illustrated that engineering majors were the most among all participants. In Figure 4 and Figure 5, it was seen that the majority of the participants were from Japan and are those who use Japanese language most easily. Figure 6 and Figure 7 showed that the majority of participants were between 23 to 25 years old and most of participants have stayed at West Virginia University less than one year.

According to the narrative answers in paper survey questions, some additional 
adjustment problems were underlined by the comments from students. Question 1 in the M.I.S.P. Inventory said: “Do you feel that the statement which you have marked provided a fairly complete picture of the problem areas currently troubling you?” One student listed the following problems:" Communication problems with friends, classmates and roommates; Lack of common topics, understanding U.S. culture and different college life style; Stress from competitive coursework.” One Japanese student said: “There is a small Japanese community here, and if I can not make good communication with them, I will feel more lonely.” One student listed “Tuition increases higher every year.” And one student mentioned "racism" as their additional concerned.

Question 2 in the M.I.S.P. Inventory said: "Do you feel that this procedure of helping you identify problem areas is worthwhile, even though you might not have enjoyed checking the statement?” Ten students thought it was worthwhile to complete this survey, and it helped them figure out their problems, because it covered the problem areas they have. Two students particularly mentioned that the survey questions helped them realize some problems they had never realized previously. One student added his comments as: "There are so many factors and problems that have to be solved." Two students made the following comments. "Most problems are impossible to solve. I should have known them before I came to the U.S.A." "I feel that some problems are hard to resolve, and some might not be able to resolve at all.” 


\section{Chapter 4}

\section{DISCUSSION}

\section{Limits of Research}

West Virginia University is located in Morgantown, a city with comparatively small international student population. From 2002 to 2005, the proportion of international students enrolled in West Virginia University ranged from $4.8 \%$ to $5.8 \%$ of total student population. Based upon the fact that there are a relatively small proportion of international students studying at West Virginia University, the sample size of this research was limited. This small sample may not be representative enough to generalize the results to a larger population.

Another reason for limited sample size was technical difficulties. Originally the online survey supported by WebCT was relied upon to collect data from the target population. Students received the survey request through their email boxes, and it was likely that many ignored their emails. Or, they may have felt impatient to complete the whole questionnaire, owing to the old version of WebCT that made questions look tedious. When paper surveys were distributed, it was the time that most of the international students went off campus for a holiday, so it was difficult to get hold of them through emails or personal contact. Even though attempts at multiple places were used to look for as many international students on campus as possible, there were still a lot of them missed.

Thus, the current research was limited and applies to the students who 
participated in this research at West Virginia University. Future replication research may provide a larger sample size, by which more data will be collected for statistical analysis and more international students will have the chance to provide more direct and constructive feedback. Such information can be of benefit to student affairs offices. Implication from Correlation Results

According to the statistical results, significant correlations were small, only in the areas of Academic Record Problems and Social Personal Problems, whereas the non-significant correlations covered the majority of areas. Thus, the following conclusion can be made that for the 33 participants at West Virginia University. Their academic achievement was correlated with their adjustment problems in (1) Academic Record and (2) Social Personal areas. The more problems identified in these two areas, the lower their GPA reported.

Implication for Counseling Services

The data from the Carruth Center of Counseling showed the lower proportion of international students who went to seek counseling services than non-international students at West Virginia University. From students' feedback in the survey (see Figure 1), “counselor" only ranked the $8^{\text {th }}$ among the first choices as the priority order to ask for help, and ranked $4^{\text {th }}$ as among students' $2^{\text {nd }}$ choices. It was indicated that counseling service at West Virginia University was not sufficiently used by international students.

Besides the reason of small international student population at West Virginia University, there were some other reasons to explain why international students were 
more willing to turn to fellow students from their home countries other than going to counseling center. Mori (2000) pointed out that because many international students have a strong sense of being “outside” in the U.S., they were either not informed of services or resources available on campus, or they were reluctant to register for counseling services. Such reluctance may reflect cultural difference in which they are "not assertive enough to seek for help by themselves. They usually perceive professionals as strangers (Charles \& Stewart, 1991). In some cultures, psychological disturbances are considered to be disgraceful, with connotations of personal weakness, immaturity, and even the shame for the whole family (Mori, 2000). It is hard for them to disclose and discuss these personal issues in front of student affairs professionals.

It is recommended that the counseling service at West Virginia University take into consideration of the particular characteristic of international student group on campus, keeping in mind that international students experience extra stress from adapting to a new culture, and their stress involves social and emotional determinants as well as academic issues (Khoo \& AbuRasian, 1994). Counselor trainings, such as “cultural self-awareness”, are good for counselors to reduce the potential prejudice and biases (Mori, 2000).

\section{Implication for Academic Advising}

The study by Nelson (2003) on "effect of crisis intervention on the retention of students" showed that the effectiveness of counseling services to international students was tied to student retention and academic achievement. From the statistical results of correlation relationships, from the 33 participants at West Virginia University, their 
academic record problems and social personal problems were negatively correlated with their GPAs. However, from the students’ feedback in the survey (see Figure 1), none of them put "advisor" as their first choices when asking for help, and "advisor" only ranked the $2^{\text {nd }}$ as their $2^{\text {nd }}$ choice. It was indicated that international students on campus paid enough attention to advising services, but they still preferred to go for their fellow students or family members first.

Charles and Stewart (1991) proposed two major objectives in advising international students: (1) help international students adjust to academic programs, and (2) help international students achieve academic success. From their study, it was recommended that academic advisors cognize their roles between the institutions and international students, through which, the academic achievement and goals expected by international students would be successfully handled. They also pointed out that "academic advisors can have a positive impact on international students' lives during their period of study in the United States.” Strategies need to be designed to enhance international students’ sense of involvement in academic community (Tompson \& Tompson, 1996).

The survey result of this study and the points of literature provide a persuasive evidence and reality as the motivation for advising professionals at West Virginia University to better facilitate international students’ academic performance.

\section{Implication for Recruitment and Retention}

As mentioned above, "fellow students from home countries" ranked the highest among the $1^{\text {st }}$ and the $2^{\text {nd }}$ choices as the priority to ask for help, which indicated that the 
current international students interacted within their groups quite often, and had a very strong influence on prospective students as well. To maintain the stable recruitment and retention rate, solving the adjustment problems of current student group is the foundation for recruitment project in the long run. According to Pederson, Briggs, Dreasher, Horner and Nelson (1986), student affairs professionals must be aware and sensitive to the "perceptions, needs, and concerns of prospective and enrolled international students" (P. 68) if they are to recruit and retain more international students.

Based upon the importance and benefits of having international students, from cultural, educational, and economic aspects as discussed before, student affairs leaders need to provide better support to international programs and services. They need to work closely with academic affairs, international student office, and other related services. It is crucial to enhance the ethical climate of undergraduate academic programs. Ethical is an important factor in undergraduate student retention (Shulte, Thompson, Hayes, Noble \& Jacobs, 2001).

\section{Implication for Office of International Students and Scholars}

Office of International Students and Scholars (OISS) is usually the first place to which international student are referred. From the data in Figure 1, "foreign student advisor" ranked the $2^{\text {nd }}$ among students' $2^{\text {nd }}$ choices, which indicated that the 33 participants at West Virginia University were more willing to ask for help in OISS comparing to "counselor," "advisor," "professors”, etc.

However, OISS is not the only unit from which international students could seek 
help, because this group has various needs and special situations (Charles \& Stewart, 1991). It is incorrectly assumed by some student affairs staff that the international office is the unit that is mainly responsible for international student problems (Pederson, Briggs, Dreasher, Horner \& Nelson, 1986). Student affairs staffs need to work together for all students. For example, accurate and timely services or programs are necessary to international students, and these will occur through proper training of student affairs staff (Pederson, Briggs, Dreasher, Horner, \& Nelson, 1986).

Recommendations for Future Research

Because of the small international student population at West Virginia University and technique difficulties, the present study did not obtain the maximum number of subjects to participant the research. Future research in this field should expand the sample size to be at least over 200, and seek more assistance from offices in Student Affairs in financial support, technique support, and other related resources. The M.I.S.P. Inventory was developed by Dr. John Porter in the1960s. Some of the adjustment problems in each category were not representative for current international students any more. Future research should put more effort to improve and update the inventory through inquiring and collecting feedback from current international student groups.

Graduate international students constitute a large proportion of current international students body at West Virginia University. Including graduate international students into future research will effectively enhance the accuracy of statistic results in terms of large sample size and cultural diversity representatives. It is recommended to 
conduct the replication research using only graduate international students, so that the results can be compared with the current research that used only undergraduate international students, to discover the differences of adjustment problems and academic achievement correlation between these two groups.

Although the present study was to investigate the relationship between adjustment problems and academic achievement, it provided a good foundation to develop further research in multiple fields. Such investigations might examine the relationships among environmental factors, academic retention, self-efficacy, psych-adjustment process, and other relevant constructs. These potential research topics would contribute to research fields in educational psychology, higher education, college student development, and even counseling psychology. 


\section{References}

Baloglu, M. (2000). Expectations of international students from counseling services. Paper presented at the Annual Conference of the American Psychological Association (108 ${ }^{\text {th }}$, August 4-8, 2000, Washington, DC).

Cassady, J.C. (2001). Self-reported GPA and SAT scores. ERIC Digest.

Charles, H., \& Stewart, M. (1991). Academic advising of international students. Journal of Multicultural Counseling \& Development, 19(4), 173-181.

Furnha., A., \& Alibhai, N. (1985). The friendship networks of foreign students: A replication and extension of the functional model. International Journal of Psychology, 20, 709-711.

Gauri, S. R. (2002). Meeting the educational needs of international students: A perspective from US schools. International Social Work, 45(1), 21-34.

Gillock, K. L. (1999). Factors affecting students' adjustment and attrition during the transition to college. (college dropout, school transition). Dissertation Abstracts International: Section B: The Science \& Engineering, 60(6-B), 2941.

Hannigan, T. P. (1990). Traits, attitudes, and skills that are related to intercultural effectiveness and their implications for cross-cultural training: A review of the literature. International Journal of Intercultural Relations, 14, 89-111.

Hayes, R. L., \& Lin, H. R. (1994). Coming to America: Developing social support system f or international students. Journal of multicultural counseling \& development, 22(1), 7-16.

Kalsner, L. (1992). The influence of developmental and emotional factors on success in college. Higher Education Extension Service Review, 3(2), 13p.

Khoo, P. L. S., \& Abu-Rasain, M.H. (1994). Counseling foreign students: A review of strategies. Counseling Psychology Quarterly, 7(2), 117-131. 
Lacina, J. G. (2002). Preparing international students for a successful social experience in higher education. New Directions for Higher Education,117, 21-27.

Lent, R. W., Brown, S.D., \& Hackett, G. (1994). Toward a unifying social cognitive theory of career and academic interest, choice, and performance. Journal of Vocational Behavior, 45, 79-122.

Lent, R. W., \& Maddux, J.E. (1997). Building a sociocognitive bridge between social and counseling psychology. The Counseling Psychologist, 25(2), 240-255.

Mori, S. (2000). Addressing the mental health concerns of international students. Journal of counseling \& development, 78(2), 137-144.

Nelson, K. L. (2003). Effects of crisis intervention on the retention of students at a large urban university. Dissertation Abstracts International: Section B: The science \& Engineering, 64(6-B), pp. 2932.

Open Doors (2005). http://opendoors.iienetwork.org/

Accessing date: January 25, 2006.

Pederson, D. M., Briggs, P., Dreasher, L., Horner, D. D., \& Nelson, T. (1986). Contributions of international students and programs to campus diversity. New Directions for Student Services, 86, 67-77.

Pederson, J. A., \& Neumeyer, M. H. (1948). Problems of foreign students. Sociology \& Social Research, 32, 787-792.

Pederson, P. B. (1991). Counseling international students. Counseling Psychologist, 19(1), $10-58$.

Porter, J. (1962). Abstract: The development of an inventory to determine the problems of foreign students. Unpublished report by Urban Education Alliance, Inc. at Ann Arbor, MI.

Porter, J. (1966). The manual of Michigan International Student Problem Inventory. 
Unpublished report by Urban Education Alliance, Inc. at Ann Arbor, MI.

Poyrazli, S. (2001). The role of assertiveness, academic experiences, and academic self-efficacy on psychosocial adjustment of graduate international students. Dissertation Abstracts International Section A: Humanities \& Social Sciences, $67(7-\mathrm{A})$.

Reinicke, M. J. (1986). Cultural adjustment of international students in the U.S.: A reevaluation using reformulated learned helplessness. Doctor of Psychology Research Paper, Biola University, California.

Rickinson, B., \& Rutherford, D. (1995). Increasing undergraduate student retention rates. British Journal of Guidance \& Counseling, 23(2), 161-172.

Schulte, L. E., Thompson, F., Hayes, K., Noble, J., \& Jacobs, E. (2001). Undergraduate faculty and student perceptions of the ethical climate and its importance in retention. College Student Journal, 35(4), 565-576.

Tompson, H.B., \& Tompson, G.H. (1996). Confronting diversity issues in the classroom with strategies to improve satisfaction and retention of international students. Journal of Education for Business, 72(1), 53-57.

Wang, J. (2003). A study of the adjustment of international graduate students at American universities, including both resilience characteristics and traditional factors. Doctoral Dissertation, Florida State University.

Wratcher, M. A. (1991). Freshman academic adjustment at a competitive university. College Student Journal, 25(2), 170-177. 
Figure 1

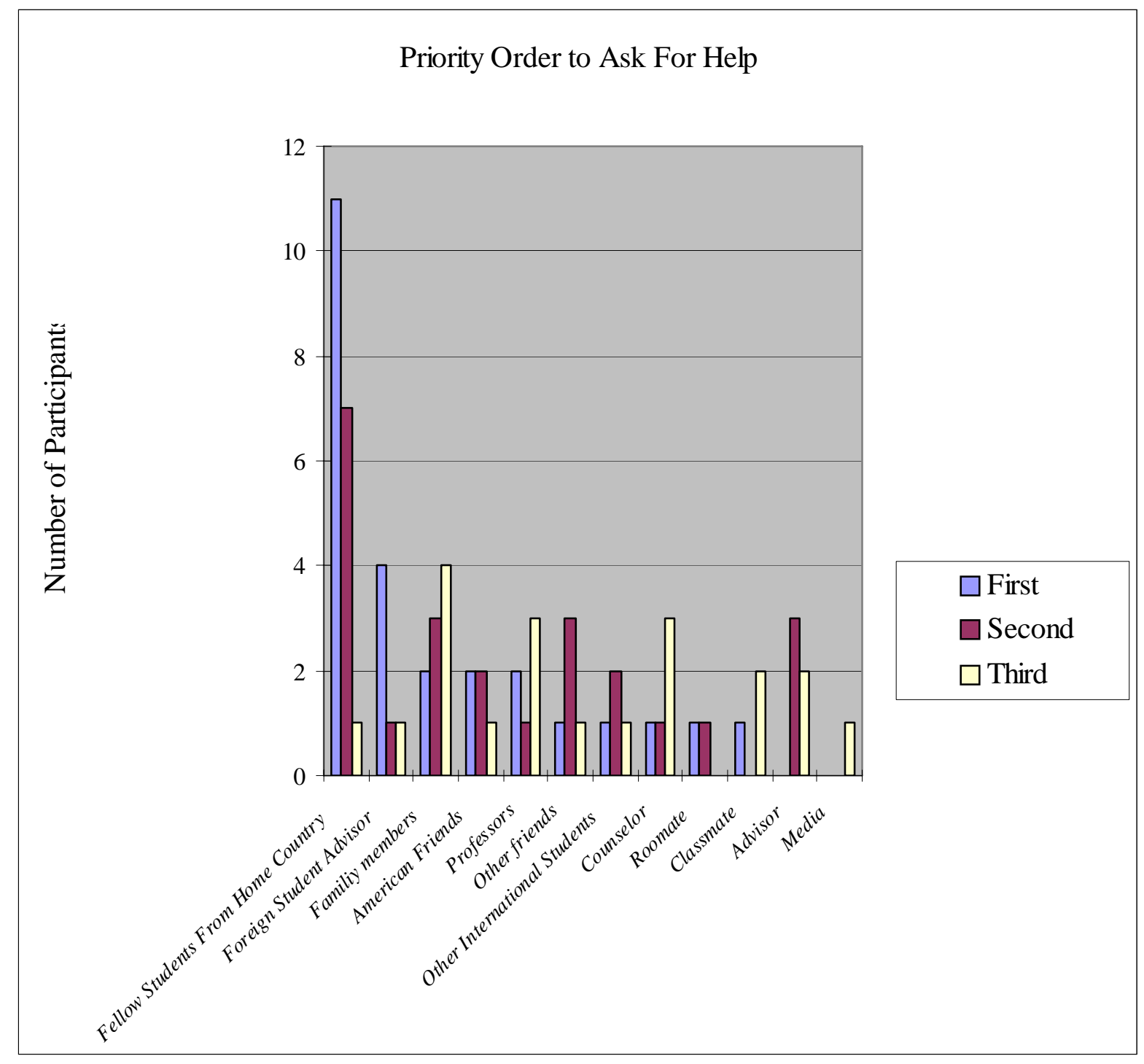


Figure 2

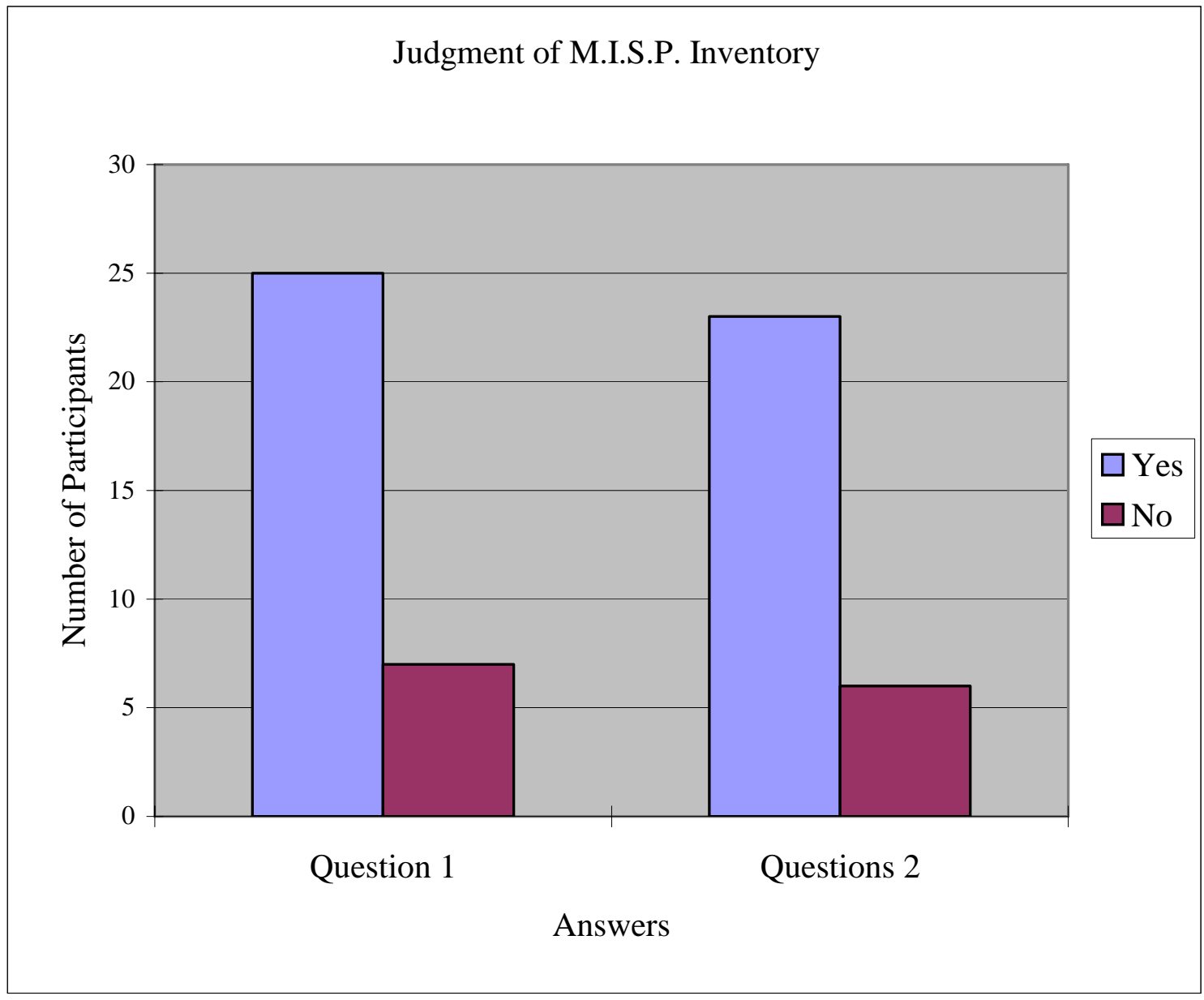

Question 1: Do you feel that the statement which you have marked provided a fairly complete picture of the problem areas currently troubling you?

Question 2: Do you feel that this procedure of helping you identify problem areas is worthwhile, even though you might not have enjoyed checking the statement? 
Figure 3

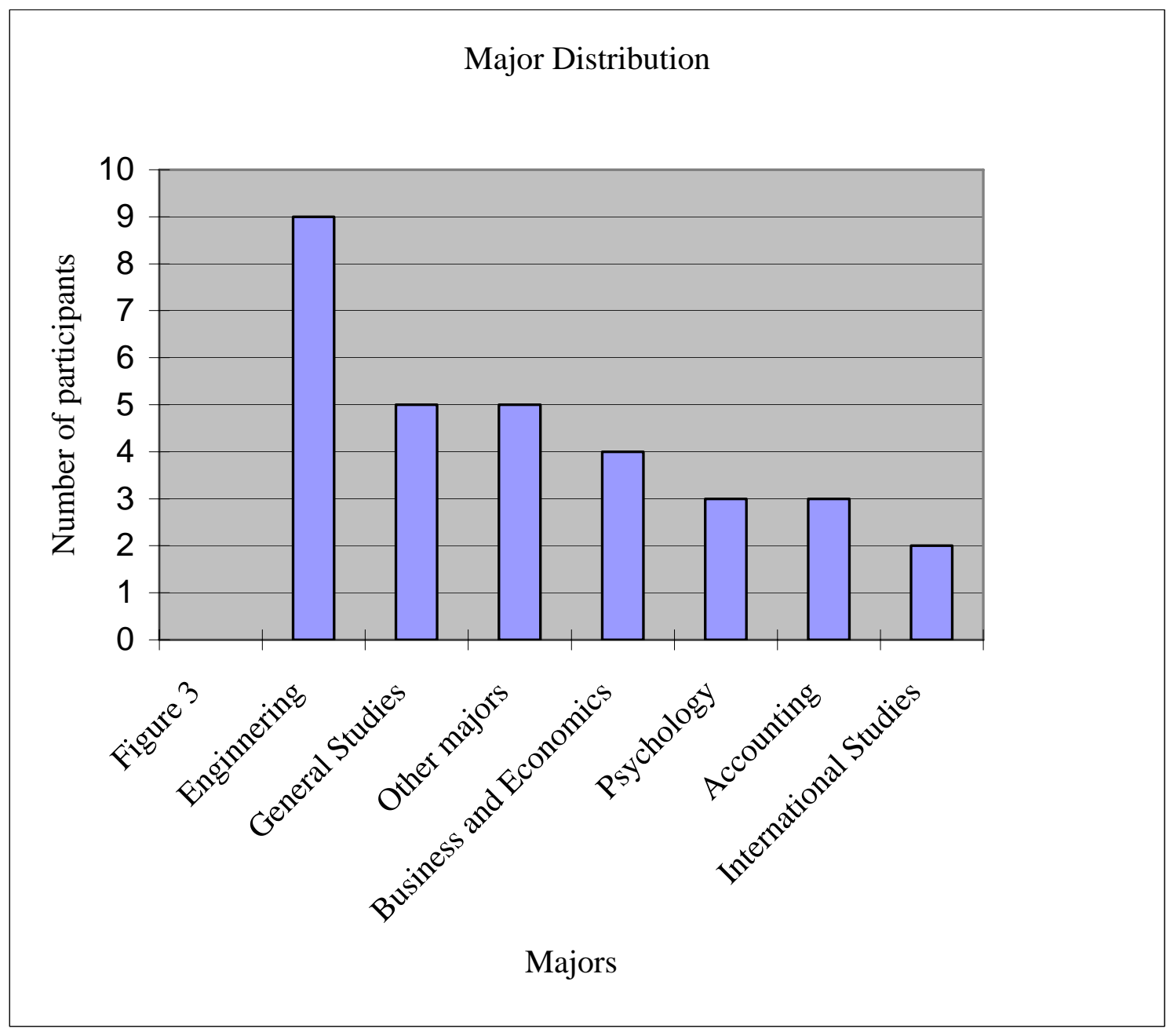


Figure 4

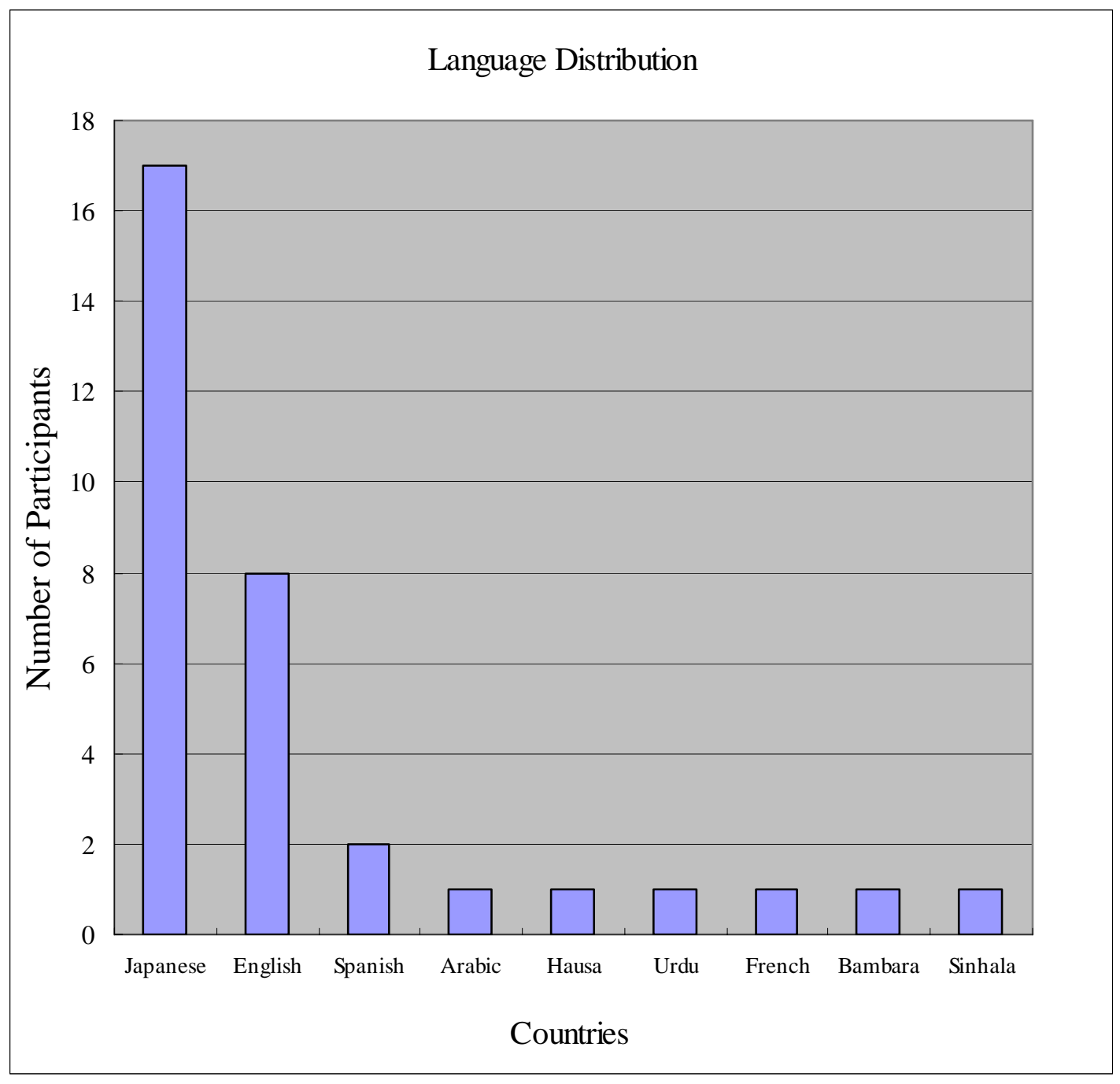


Figure 5

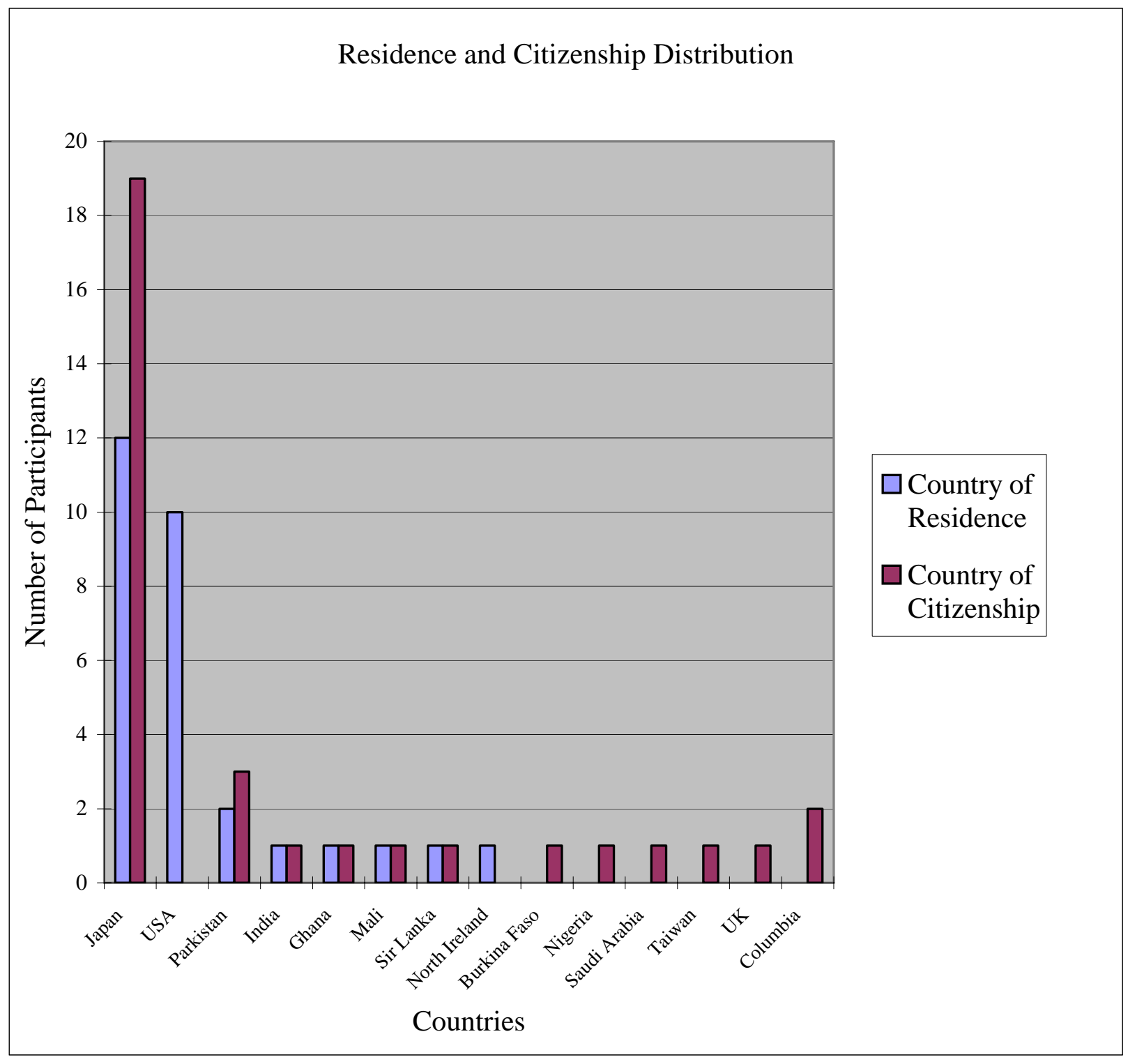


Figure 6

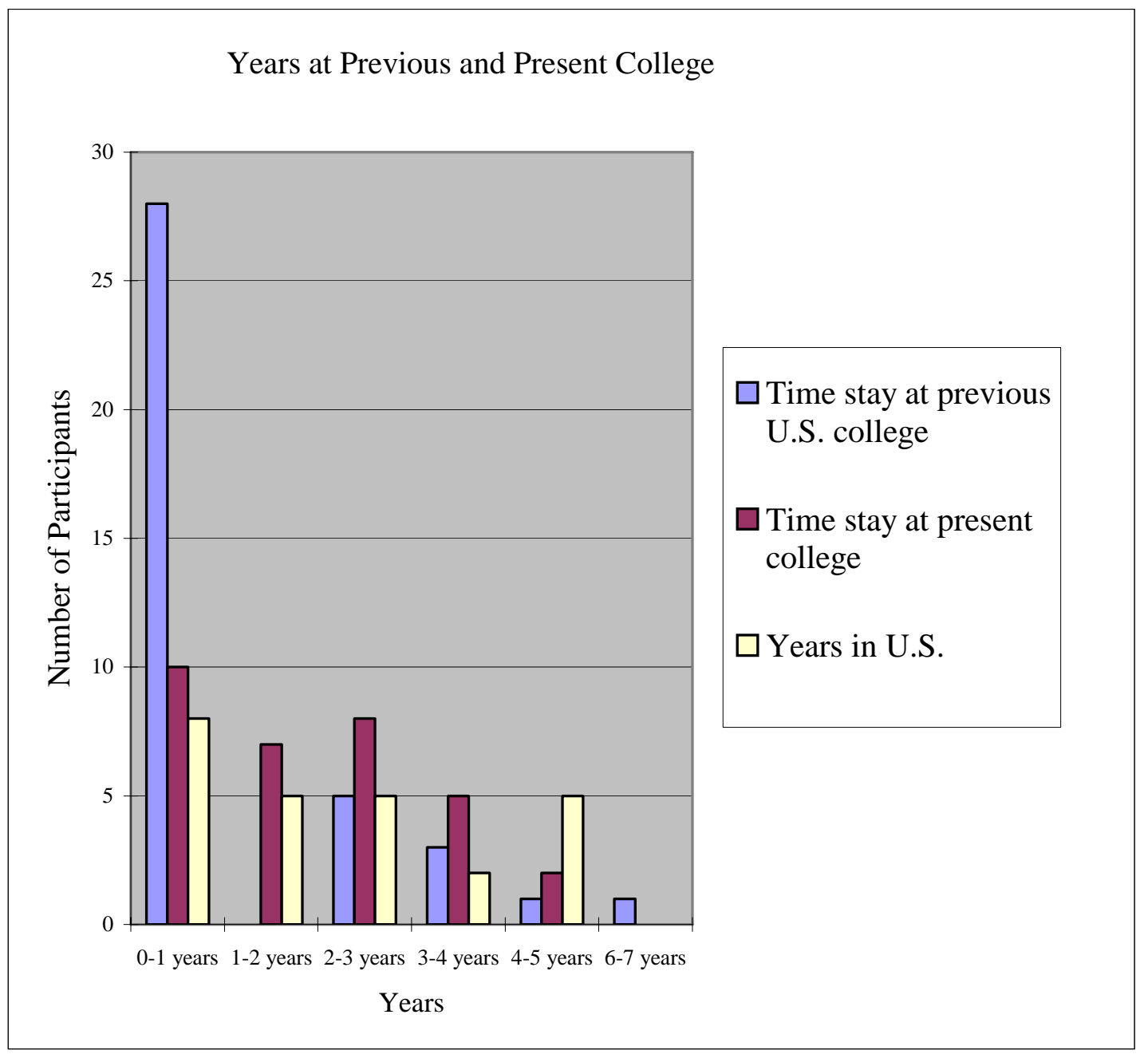


Figure 7

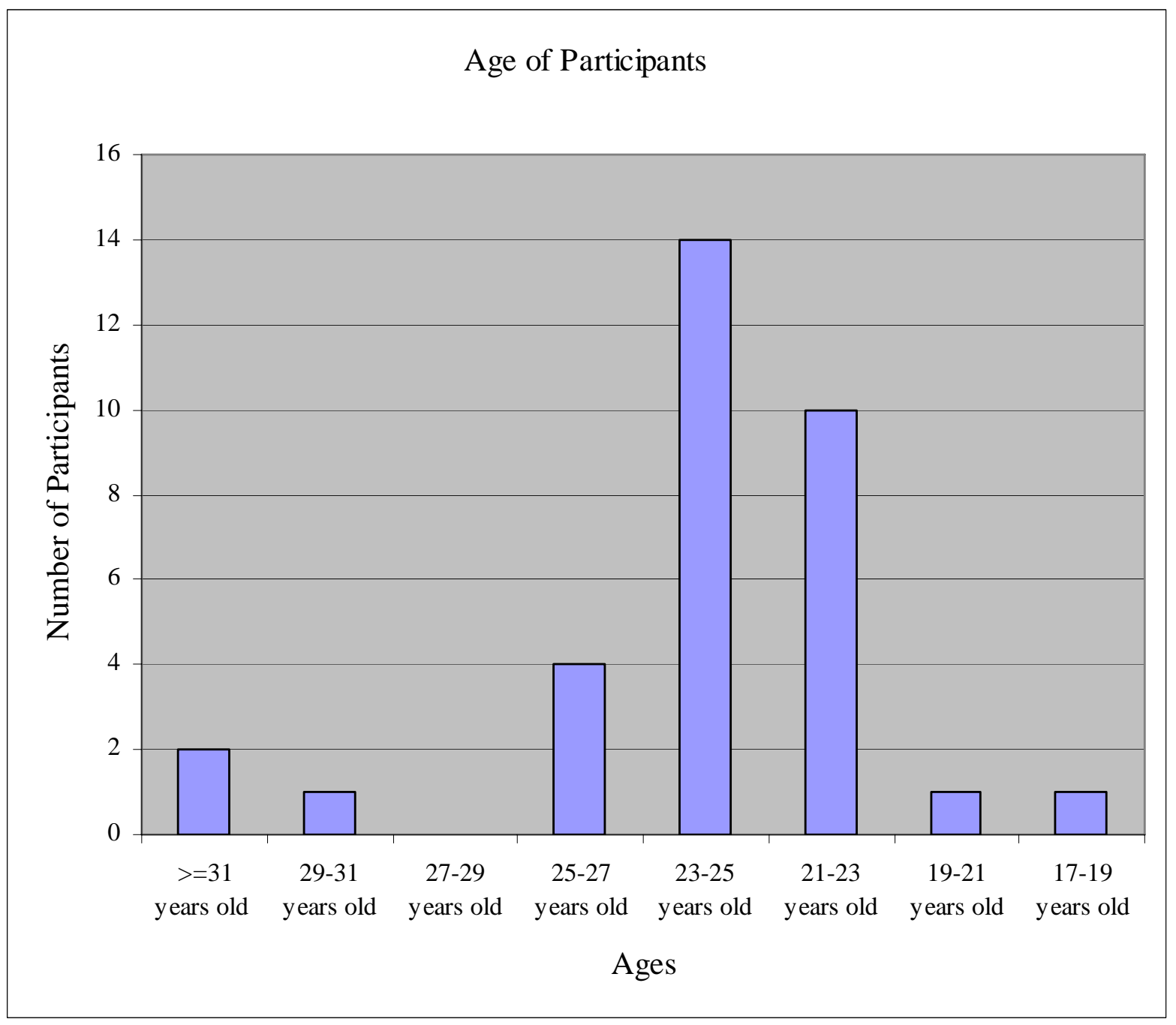

